\title{
O CONSUMO DE BATOM: UM ESTUDO NA CLASSE C
}

\author{
Claudia Rosa Acevedo de Abreu Campanario ${ }^{1}$ \\ Mônica Caparroz ${ }^{2}$ \\ Sandra Maria Martini ${ }^{3}$
}

\begin{abstract}
Resumo: A presente investigação tem o objetivo de entender quais as motivações presentes num grupo de integrantes da classe $\mathrm{C}$ pertencentes às gerações $\mathrm{Y}$ e $\mathrm{Z}$, na região sul da cidade de São Paulo, para o consumo de batom. Esta investigação apoiou-se na coleta de dados baseada em um grupo de foco e complementada por entrevistas em profundidade, com mulheres da classe $\mathrm{C}$ das gerações $\mathrm{Y}$ e $\mathrm{Z}$, de renda mensal entre $\mathrm{R} \$ 1.064,00$ e $\mathrm{R} \$ 4.561,00$. A investigação apoiou-se em referências da literatura através do entendimento do comportamento de consumo, vaidade, classe $\mathrm{C}$, gerações $\mathrm{Y}$ e $\mathrm{Z}$ e mercado de batom.
\end{abstract}

Palavras-Chave: Comportamento de Consumo, Vaidade, Classe C, Gerações Y e Z, Mercado de Batom.

\section{CONSUMER BEHAVIOR OF MAKEUP PRODUCTS FOR LIPS: AN EXPLORATORY STUDY OF CLASS C}

\begin{abstract}
This research aims to understand the motivations present in a group of members of the class $\mathrm{C}$ belonging to the $\mathrm{Y}$ and $\mathrm{Z}$ generations, in the southern region of the city of São Paulo, for the consumption of Lipstick. This research was supported in collection based on a focus group and complemented by in-depth interviews with women of the class $\mathrm{C}$ of $\mathrm{Y}$ and $\mathrm{Z}$ generations, monthly income between R \$1,064.00 and R \$ 4,561.00 data. The research was based on literature references through understanding of consumer behavior, vanity, class $\mathrm{C}, \mathrm{Y}$ and $\mathrm{Z}$ generations and lipstick market
\end{abstract}

Key-words: Consumer Behavior, Vanity, Class C, Generation Y and Z, Lipstick Mark.

\section{INTRODUÇÃO}

A ideia do tema surgiu do levantamento de informações do mercado de trabalho brasileiro, onde a mulher da classe $\mathrm{C}$ pertencente às gerações $\mathrm{Y}$ e $\mathrm{Z}$, tem grande participação e demonstra a importância de estar sempre bem apresentável, passar uma imagem de cuidado e fazer um marketing pessoal, para alavancar sua carreira e profissão.

Sabe-se que o consumo da classe C aumentou, e que $65 \%$ do investimento da mulher da classe $C$ é em educação, aparência e escolaridade no nível superior, segundo o Data Popular (2013). 
A aparência física é um tema de preocupação crescente para grande parte da população mundial. Estudos indicam que uma visão positiva sobre a beleza física de alguém, ocasiona uma tendência em atribuir a essa pessoa boas qualidades sociais e individuais.

As mulheres da classe $\mathrm{C}$ tiveram participação expressiva no consumo de itens relacionados à aparência e no movimento dos salões de beleza. Entre as jovens brasileiras, as da classe $C$, são vaidosas e mais independentes do que mulheres na mesma idade em outras classes sociais, de acordo com um estudo feito pela consultoria Data Popular (2013).

Este estudo exploratório tem o objetivo de investigar as motivações presentes num grupo de mulheres integrantes da classe $\mathrm{C}$, pertencentes às gerações $\mathrm{Y}$ e $\mathrm{Z}$, no consumo de batom. Utilizou-se a abordagem qualitativa com entrevistas em profundidade, para uma amostra de dez mulheres pertencentes à faixa etária entre 18 e 34 anos, podendo ser classificadas como Geração Y e Z (Veloso, Dutra \& Nakata, 2008) moradoras da cidade de São Paulo, na região sul.

O mercado da classe $C$, suas marcas e produtos são amplamente difundidos pela forte cobertura de mídia. Os processos pelos quais as consumidoras da classe $\mathrm{C}$ das gerações $\mathrm{Y}$ e $\mathrm{Z}$ adquirem e consomem batom ainda permanecem sem uma explicação, de acordo com a consultoria Data Populares (2013).

Este artigo é uma forma de contribuir para um maior entendimento sobre o tema e trazer informações para vários setores da economia brasileira, possibilitando às empresas um melhor conhecimento deste grupo social e entendimento do que esta consumidora deseja, em termos de produto e marca.

O Brasil ocupa a terceira posição entre os maiores mercados de produtos de higiene pessoal, perfumaria e cosméticos do mundo, perdendo somente para os Estados Unidos e Japão. O que se observa cada vez mais é que a classe C está entrando com uma enorme força no mercado de cosméticos, não que esses consumidores estejam começando agora a usar produtos de higiene e beleza; eles já usavam, mas para ocasiões especiais, a novidade é que estão incorporando a sua rotina(Data Popular, 2013).

Como apontam os dados do projeto Vozes da Classe Média, (SAE,2012), entre os anos de 2004 e 2010, 32 milhões de pessoas obtiveram elevação socioeconômica , especialmente nas classes $\mathrm{C}$ e D. A classe $\mathrm{C}$ apresentou uma ascensão notável e um fortalecimento poucas vezes visto em uma classe mediana, pois no ano de 2003 representava cerca de 63,9 milhões de pessoas e, em 2012 , verificou-se que estava constituída por 105,4 milhões de pessoas (SAE, 2012). 
No presente trabalho optou-se por estudar mulheres da classe C, nascidas entre 1980 e 1996, com idades entre 18 e 34 anos, pertencentes às gerações Y e Z, na data da coleta de dados (outubro de 2014), pois representam uma parcela da população que potencialmente compra batom.

A utilização do conceito de gerações é fundamental para se compreender as transformações ocorridas no ciclo de vida de um indivíduo, e para focar-se uma estratégia de marketing ou venda de qualquer produto, especialmente os do setor de cosméticos como o batom. onde a aquisição da primeira maquilagem ocorre a partir da adolescência a partir dos 11 anos de idade.

A geração Y e Z são caracterizadas por forte influência de tecnologia no seu cotidiano, além de traços de individualidade constituídos como forma de ter a sensação de pertencimento social (Lancaster, 2011, Santos, 2011; Meyers, 2005; Damatta, 2000) associado ao ato de obter um bem pessoal, como por exemplo o batom.

O batom é um produto de maquilagem do setor de cosmético, tido como a extensão da personalidade de um individuo (Jato \& Gil, 2007).

\section{FUNDAMENTAÇÃO TEÓRICA}

Consumo é um processo cuja significação social está em proporcionar uma referência para a construção da identidade social dos indivíduos. O consumo não é um ato individual e nacional, mas um processo social, possibilitando o posicionamento do indivíduo em relação ao seu contexto social e cultural (Tofani, 2008 apud Abranches, 2010).

Para grande parte dos autores o consumidor submete-se a vários estágios que antecedem o consumo, prevalecem durante a compra e influenciam após o uso. E, são estes estágios o chamado comportamento do consumidor.

Para Kotler e Keller (2012) uma vez que o propósito de marketing centra-se em atender e satisfazer as necessidades e aos desejos dos consumidores, torna-se fundamental conhecer o seu comportamento de compra. Conhecer este comportamento é um facilitador para as empresas desenvolverem suas estratégias de marketing.

Para Blackwell, Miniard e Engel (2008), o sucesso de um produto ou serviço, depende da habilidade e atitudes dos envolvidos no processo de aquisição e uso dos bens adquiridos. Para estes autores o comportamento do consumidor é a análise de porque, quando e onde compram e ainda, as atitudes que desempenham para poder adquirir um produto ou serviço.

55 Revista Competitividade e Sustentabilidade - ComSus, Paraná, v. 3, n. 1, p. 53-71, Jan /Jun. 2016. 
Segundo Blackwell, Miniard e Engel (2008), existem sete estágios que envolvem o consumidor antes, durante e após a compra. Enquanto para Kotler (2012) existem apenas cinco estágios. Os dois autores concordam que existe o reconhecimento do problema, a busca de informações sobre o produto, a avaliação das alternativas disponíveis para o consumo, a compra e o resultado pós compra. Porém, para Blackwell, Miniard e Engel (2008) acrescentase neste processo o consumo e o descarte do que não foi consumido.

Segundo Kotler e Keller (2012), o processo de consumo inicia-se no momento que o consumidor reconhece a necessidade de alguma coisa e a transforma em desejo.

Para Blackwell, Miniard e Angel (2008), neste momento de reconhecimento da necessidade, o indivíduo percebe a diferença entre aquilo que julga ser ideal para viver e sua real situação. Para atrair a atenção do consumidor, as empresas devem mostrar que seus produtos apresentam uma solução maior do que o custo para obtê-lo.A busca por informações pode ser interna ou externa de acordo com Blackwell, Miniard e Engel (2008). As internas são as experiências já vividas e a memória de cada um. As externas são as publicidades, mercados, grupos sociais. A velocidade com que esta busca é feita está diretamente ligada ao interesse em obter o produto. Com este conhecimento o consumidor distingue uma marca da outra, os atributos de cada mercadoria e analisa os benefícios oferecidos.

Em seguida surge a avaliação das alternativas disponíveis para compra. Para Kotler é nesta situação que o consumidor faz comparações entre os vários produtos existentes, enaltecendo os atributos que atendam ao interesse de compra da pessoa. O consumidor avalia nesta fase os benefícios que o produto pode gerar em comparação aos benefícios procurados pelo indivíduo, como a análise de alternativas feita e hora da compra. Neste momento, o consumidor já sabe escolher um ponto de venda, um vendedor, a quantidade, a forma de pagamento e a compra do produto segundo Blackwell, Miniard e Engel (2008).

Segundo Kotler e Keller (2012), compras frequentes envolvem menos decisões e deliberações. Um ponto importante a ser avaliado é o processo pós compra ao qual o consumidor se submete após conhecimento e utilização do produto, o consumidor irá demonstrar satisfação ou insatisfação em adquirir o produto - serviço. Nesta situação podem surgir questionamentos de arrependimento (“Eu comprei um bom produto?") tanto quanto afirmações de felicidade ("Eu fiz a melhor escolha").

Satisfazer-se ou não com a aquisição relaciona-se, também, aos fatores sociais que influenciam neste processo como opiniões de amigos, familiares, grupos sociais. Segundo Blackwell, Miniard e Engel (2008), entre a fase de compra e pós-compra existe um nível de 


\section{O CONSUMO DE BATOM: UM ESTUDO NA CLASSE C}

consumo, que consiste na utilização do produto adquirido. Este consumo pode ser feito de forma imediata ou posterior, mas neste momento o produto deverá surpreender o cliente para que ele seja um consumidor satisfeito. Caso contrário, o indivíduo poderá ficar insatisfeito, o que dará maiores chances de atuação da concorrência.

Kotler (2012) afirma que todo processo de compra é influenciado tanto pelos fatores culturais, sociais e pessoais, quanto pela urgência, motivação, desejo e envolvimento do consumidor na aquisição do bem ou serviço.

Solomon (2002), Chiffman e Kanut (2000), também, compreendem que o indivíduo como consumidor, sofre influências pessoais, sociais e culturais.

Toda decisão de compra conta com a influência de fatores sociais, que segundo Kotler e Keller (2012), são grupos de referência como família, status, reputação, papel, posição e grupos sociais em que o consumidor está inserido.

Com base em Blackwell, Miniard e Engel (2008), estas influências sociais se dão pela cultura em que vive o cliente, pela classe social, e pela situação social e econômica em que se encontra o consumidor. Para estes autores tais fatores contribuem para que a pessoa consuma visando, além dos benefícios reais do produto, uma integração social, ou seja, são fatores que estabelecem os padrões consumistas de determinados grupos sociais.

Compras também são influenciadas por características pessoais que de acordo com Kotler e Keller (2012), são a idade, a condição financeira, estilo de vida, personalidade e c valores de criação. Blackwell, Miniard e Enggel (2008), complementam essa definição com a motivação para compra, o conhecimento do produto e as atitudes sobre uma determinada marca ou produto. Estes autores definem tais pontos como influências pessoais, por considerarem que são variáveis diretamente ligadas ao consumidor, que só podem ser alteradas conforme interesse e empenho da pessoa, indiferente da relação que este estabelece em seus grupos de relacionamentos.

As influências pessoais, segundo Sheth, Banwari e Newman (2001), processam-se de forma integrada, ou seja, a associação de informações do produto às experiências já vividas. Estas variáveis pessoais incidem diretamente sobre o processo de motivação do consumidor, e é essa motivação que irá gerar as compras baseadas nas necessidades reais, no impulso e no desejo, Sheth, Banwari e Newman (2001). Crenças próprias de um consumidor definem um comportamento padrão e aceitável para a pessoa. Enquanto crenças e normas partilhadas por grupos de referencia dos quais o indivíduo faz parte, definem uma forma de comportamento aceitável para um grupo, o que resulta em interferência social na decisão de compra. "Cultura, 
subcultura e classe social são fatores importantes no comportamento de compra" (Sheth, Banwari e Newman (2001), pag.29).

Segundo Kotler (2012), esta cultura vem com a pessoa desde o seu nascimento e à medida que os anos vão passando novos valores, percepções e referências vão sendo agregados a personalidade da pessoa. Esta influência externa é adquirida na família, na escola, com os amigos. Ainda, alguns fatores que influem neste comportamento estão ligados a cidade natal, aos pais, ao estilo de vida que pretendem seguir. Além destes, a religião, raça, opção sexual, visão de futuro e classe social incidem sobre os hábitos de compra. Por isso, a escolha deste artigo, num grupo de mulheres integrantes da classe C, para entender-se quais as motivações para o consumo do produto batom neste grupo de referência.

Apesar de a vaidade ser realmente inerente ao ser humano (SCHOUTEN, 1991), nem sempre ela foi bem vista como pode ser verificado na sua definição no dicionário Aurélio: “qualidade daquilo que é vão (fútil, insignificante, que só existe na fantasia, falso, ilusório e inútil)".

A vaidade tem se apresentado como um dos temas dominantes na cultura ocidental (Netmeyer et al., 1995). Segundo Netemeyer et al,. (1995), a vaidade é muito relacionada ao materialismo justificando a importância de estudos sobre este construto e seu impacto no comportamento do consumidor.

De acordo com Netemeyer, Burton \& Lichtenstein (1995), a vaidade é definida através de quatro traços: preocupação excessiva com a aparência, visão positiva (e exagerada) da aparência física, preocupação excessiva com a realização e alcance de metas e a visão positiva da realização dessas metas.

Mowen, Longoria \& Sallee (2009), utilizaram duas das escalas desenvolvidas por Netemeyer et al.(1995) para avaliar a vaidade física: preocupação com a aparência (vanity concern) que se refere à preocupação exagerada com a aparência física e visão vaidosa (vanity view) que se refere à visão exageradamente positiva da aparência física de uma pessoa.

Esses construtos foram tratados separadamente, pois como foi demonstrado no estudo de Mowen et. al.(2009), a escala desenvolvida por Netemeyer et. Al . (1995), é bidimensional, ou seja, os construtos apresentados não são facetas da dimensão vaidade, mas tratam-se de duas dimensões diferentes.

Classes Sociais são as divisões estabelecidas na sociedade, segundo critérios de renda, de acesso aos bens de consumo, moradia, educação e saúde (IBGE, 2013). 
Mais de 130 milhões de brasileiros (68\% da população nacional) com renda familiar entre $\mathrm{R} \$ 1.126,00$ e $\mathrm{R} \$ 4.824,03$, compõe as classes sociais C e D do Brasil.

A melhoria da renda do brasileiro aumentou o potencial de consumo das classes $\mathrm{C}$ e $\mathrm{D}$, que já representam um mercado de $\mathrm{R} \$ 834$ bilhões, segundo levantamento feito pelo Instituto Data Popular (2013).

A classe $\mathrm{C}$, também conhecida como nova classe média vêm adquirindo bens de consumo considerados restritos às classes $\mathrm{A}$ e $\mathrm{B}$, enquanto a classe $\mathrm{D}$ ou classe média baixa passa a adquirir produtos, antes consumidos pela classe $\mathrm{C}$.

Mas quem são estas pessoas da classe C e D? São trabalhadores, em sua maioria formal (CLT, que trabalham entre oito e quatorze horas por dia). Este público demora mais tempo para casar, e sua família não é composta por mais de quatro pessoas (pai, mãe, e dois filhos). Valorizam os momentos de lazer em família, bem como o consumo que proporcionem bem estar e comodidade (Fanganelo, 2010).

Quando este público torna-se o centro das discussões de consumo e marketing é necessário saber que não se trata apenas de um conglomerado de pessoas que consome cada vez mais. É um público que revolucionou o sistema econômico nacional.

As empresas precisam se adaptar às exigências e particularidades destes consumidores, e segundo critérios da Fundação Getúlio Vargas, ainda, teve que aprender a trabalhar com crédito facilitado - financiamento de longo prazo (Agostinie Meywer, 2010). As classes C e D constituem uma camada da população que desprezam os produtos mais baratos, incluindo os "piratas", porque duram pouco e os mais sofisticados e caros estão fora da lista de compras porque comprometem a renda desse consumidor, ou seja, as empresas estão tendo que reinventar o seu mix de produtos (Fanganelo,2010).

Segundo Agostini e Meyer (2010) 99\% das casas da população de classes média e média baixa, têm televisão, $87 \%$ têm celular e $40 \%$ têm computador com acesso à internet. $\mathrm{O}$ principal meio de informação deste público ainda é a televisão e as informações "boca a boca”. Grande parte de seus recursos financeiros são investidos em eletroeletrônicos (44\%), seguidos por eletrodomésticos (36\%) e em terceiro livros e revistas (24\%). Este último dado mostra a ascensão cultural desta nova consumidora. O Cartão de crédito, que há alguns anos atrás, resumia-se às classes $\mathrm{A}$ e $\mathrm{B}$, é uma nova forma de pagamento utilizado por $68 \%$ das pessoas pertencentes às classes médias. Estes níveis sociais emergentes no país geram uma revolução no varejo, nas empresas e na economia nacional. Trabalham mais, ganham mais e

59 Revista Competitividade e Sustentabilidade - ComSus, Paraná, v. 3, n. 1, p. 53-71, Jan /Jun. 2016. 
fazem circular mais dinheiro no país. É um público que merece atenção por partes das estratégias de marketing e das empresas.

Segundo o Data Popular (2013), o perfil da mulher da classe C que em 2036 compartilhará igualmente com os homens as despesas domésticas, investirá mais em estudos, terá maior participação no mercado de trabalho e aumentará o poder de compra. A projeção está ligada ao crescimento de renda feminina da chamada nova classe media brasileira nos últimos cinco anos. Enquanto as mulheres registraram uma elevação de 25,6\% no período, os homens apresentaram uma expansão de apenas $15 \%$.

O levantamento esboçou um crescimento maior do grupo social para 2014, somando um total de $58,3 \%$ do povo brasileiro, contra os 53,9\% atuais. Hoje há uma participação de $40 \%$ das mulheres e $60 \%$ dos homens em casa, mas daqui a 25 anos exibirá uma situação equilibrada, $50 \%$ a 50\%, na classe C, declara Renato Meirelles, Diretor do Data Popular (2013).

Distribuir indivíduos em gerações é uma ação realizada no Marketing, embora haja algumas divergências, entre autores da área na bibliografia.

Não há uma consonância dentro da literatura de Marketing quanto ao número de faixas geracionais existentes, porém este artigo se aterá com o que se observou em um conjunto de obras (Veloso, Silva \& Dutra, 2011; Hudson, 2010; Veloso, Dutra e Nakata, 2008) onde se verificou as seguintes gerações classificadas como: Baby boomers, geração X, geração Y e geração Z.

Os Baby boomers, são os filhos da Grande geração e geração silenciosa, sendo pessoas nascidas nos anos 50 e início dos anos 60. Já a Geração X são as pessoas nascidas no final da década de 1960 e início da década de 1970. Já a Geração Y são pessoas nascidas nos anos 1980 e 1990. Já a Geração Z são os indivíduos nascidos entre 1990 e 2000.

$\mathrm{Na}$ ausência de consenso entre autores quanto às idades correspondentes a esses grupos optou-se por usar como parâmetro de determinação etária de gerações à classificação realizada por Veloso, Dutra e Nakata (2008) onde a geração Y corresponde aos nascidos entre os anos de 1978 a 1988, e a geração Z aos nascidos entre 1989 a 1999.

Conforme a literatura, a geração Y demonstra atitudes de inquietação, contestação e, às vezes, de insubordinação sobre diversos aspectos do cotidiano das organizações atuais. Essa geração rejeita tradicionais intervenções educativas em favor da interatividade e modelagem de formas de aprendizado que atendam suas necessidades. Indivíduos da geração Y estão habituados a compartilhar informações e a estarem em contato com as pessoas no 
ambiente virtual, dentro e fora das organizações (Zemke, Raines; Filipczak, 2000; Coimbra; Schikmann, 2001; Smola; Sutton, 2002).

A geração Y é descrita como uma geração voltada para resultados. Os jovens têm como características principais a simultaneidade, a capacidade de realização de várias atividades, uma cultura digital arraigada a seu estilo de vida - foi a primeira geração a ter acesso ao computador e a internet - ao universo da informação (Oliveira, 2010; Veloso, Dutra \& Nakata, 2008).

O individualismo é uma das marcas da população que a representam pelos atributos pessoais, que são projetados por vezes, em seus bens materiais, essa reação constitui a sua forma de posicionar-se ao mundo e obter a sensação de pertencimento social (Lancaster, 2011), Santos, 2011; Meyers, 2005; Damatta, 2000) .Este fator pode ser explicado, pois a geração Y vive uma espécie de isolamento acentuado em relação ao grupo social (Oliveira, 2010) privilegiando atividades individuais em ambientes mais controlados.

A geração Y tem o consumo como prática habitual; associado a uma tarefa emocional e prazerosa, ele é realizado sem se dar prioridade à marca dos produtos, e tem como objetivo principal as consequências finais ocasionadas pela aquisição. Os hábitos de consumo da geração têm uma configuração distinta das gerações anteriores por se estruturar com uma visão mais ampla quanto à estimulação de Marketing. Devido à expressiva presença de aparelhos tecnológicos propagando ideais da imprensa, desenvolveu-se uma propensão ao consumo para satisfação da vontade do exibicionismo demostrada por seus membros(Mittal, Newman \&Sheth, 2001).

A composição da Classe C é heterogênea mas formada por jovens da geração Y, os quais compreendem $60 \%$ da população total da classe, apresentam autonomia de gostos e preferências e buscam cercar-se de objetos que afirmem seu potencial aquisitivo, no caso de bons batons (cremoso, líquido ou brilho para lábios) associados a atributos como independência, realização pessoal, força e status (Neri, 2011).

A geração $\mathrm{Z}$ é descrita como uma geração correspondente à idealização e nascimento da World Wide Web, criada em 1990 por Tim Berners-Lee (nascidos a partir de 1991) e no "boom" na criação de aparelhos tecnológicos (nascidos entre o fim de 1992 a 2010). A grande nuance dessa geração é zapear, tendo várias opções, entre canais de televisão, internet, vídeo game, telefone e MP3 players, tablet, Iphone, Ipad.

As pessoas da Geração Z são conhecidas por serem digitais acessando a internet de suas casas, e pelo celular extremamente conectadas a rede.

61 Revista Competitividade e Sustentabilidade - ComSus, Paraná, v. 3, n. 1, p. 53-71, Jan /Jun. 2016. 
Garotas e garotos da Geração Z, em sua maioria, nunca conceberam o planeta sem computador, chats, telefone celular. Por isso, são menos deslumbrados que os da Geração Y com chips e joysticks.

Sua maneira de pensar influenciou-se desde o nascimento. Diferente de seus pais sente-se à vontade quando ligam ao mesmo tempo a televisão, o rádio, o telefone, música e internet.

Outra característica essencial dessa geração é o conceito de mundo que possui desapegado das fronteiras geográficas. Para eles, a globalização não foi um valor adquirido no meio da vida a um custo elevado. Aprenderam a conviver com ela já na infância. Como informação não lhes falta, estão à frente dos mais velhos, concentrados em adaptar-se aos novos tempos.

Formado por adolescentes - futuros consumidores - esse grupo já desenha algumas tendências que devem despertar a atenção do mercado. Mantendo algumas características dos jovens da geração $Y$, a geração $Z$ está cada vez mais preocupada com a sustentabilidade e disposta a não pagar por produtos e serviços que podem ser encontrados gratuitamente na internet.

O conceito de gerações, antes muito utilizado pela área de recursos humanos, ganha importância também no mercado. Mesmo não sendo possível rotular pessoas apenas de acordo com a sua faixa etária, a definição pode facilitar o conhecimento e o desenvolvimento da estratégia das empresas.

Semelhante à geração $\mathrm{Y}$, a geração $\mathrm{Z}$ também é inquieta, menos fiel às marcas $\mathrm{e}$ acostumada a fazer tarefas múltiplas. A geração Y quer as coisas rápidas, e a geração Z muito mais, ela não sabe o que é o mundo sem tecnologia" aponta Paulo Carramenha, diretor Presidente da GFK CR Brasil, em entrevista ao Mundo do Marketing (2013).

Para as empresas, é importante entender que a característica fundamental da geração $\mathrm{Y}$ e $\mathrm{Z}$, é que eles querem pagar cada vez menos por produtos e conteúdo. Fazer downloads gratuitos de músicas, filmes e livros, e que não, pagam por isso com a mesma frequência que a geração X."O que eles mais compram são produtos relacionados à moda e à tecnologia, especialmente celular. Além disso, apesar de os jovens da geração $Z$ ainda não estarem inseridos no mercado de consumo, eles influenciam os pais na hora da compra, fazem pesquisa na internet e vão à loja física.

Outra tendência que já se desenha entre os indivíduos da Y é o apelo por produtos e serviços sustentáveis. “Os jovens estão mais preocupados com o meio ambiente e com causas 
sociais, mais do que a geração X, que é muito consumista. Eles querem escolher melhor, saber que a marca contribui para a sustentabilidade e buscar o consumo consciente", diz Carramenha, da GFK CR Brasil (2013).

A transparência das marcas também é um atributo muito valorizado pelos jovens da geração Y. As marcas que souberem entregar conteúdo para esse consumidor, se darão bem. As empresas que querem se comunicar com o jovem têm que fazer algo de que eles gostem e estejam ligados à marca.

Segundo a classificação do IBGE - Instituto Brasileiro de Geografia e Estatística (2013) há classes de atividades e descrições dos produtos, o código 2063.2190 é o que específica os produtos de maquilagem para os lábios (batom cremoso ou líquido; brilho para lábios).tema de estudo de meu artigo.

O batom é um cosmético usado para dar cor aos lábios. Com ou sem brilho, realça a boca e é disponível em várias cores e marcas, adequando-se a diversos gostos.

O nome vem do francês bâton, literalmente "bastão", embora o cosmético não seja chamado assim em francês. As mulheres da Antiga Mesopotâmia (7.000 à 5.500 A.C.) foram as primeiras mulheres a inventarem e usarem batom. Colorir os lábios começou a ganhar popularidade na Inglaterra do século 16.

Durante o reinado da rainha Elizabeth I ter os lábios vermelhos brilhantes e um rosto branco e austero tornou-se moda. Até o final do século 19, Guerlain, uma empresa de cosméticos francesa, começou a fabricar batom.

O primeiro batom comercial foi inventado em 1884, por perfumistas em Paris na França.

$\mathrm{Na}$ Inglaterra o batom começou a ser moda no final de 1921. No século 19, o batom era colorido através de corante carmim, extraído de cochonilha nativas do México e da América Central.

Antes do final do século 19, as mulheres só usavam maquiagem em casa. Em 1912 as mulheres americanas já começaram a considerar batom como aceitável, embora um artigo no New York Times comentava sobre a necessidade de se usar batom com cautela.

Em 1915, o batom foi vendido em cilindros metálicos que foram inventados por Maurice Levy.

Em 1923, o primeiro tubo giratório foi patenteado por James Bruce Mason Jr. em Nashville, Tennessee. Elizabeth Arden e Estee Lauder começaram a vender batom em seus salões.

63 Revista Competitividade e Sustentabilidade - ComSus, Paraná, v. 3, n. 1, p. 53-71, Jan /Jun. 2016. 
Com a fabricação, preços baixos, facilidade de uso, ascensão da fotografia e a disseminação do item por meio de famosas atrizes de cinema, entre as décadas de 1930 e 1950 (Sarah Bernhardt, Marilyn Monroe e Elizabeth Taylor), os batons finalmente ocuparam espaço na moda tornando-se um item presente em todo o mundo.

Relativamente baratos, fáceis de encontrar, simples de usar e com grande poder de modificar sutil e/ou drasticamente o visual - na sociedade contemporânea os batons são, um dos mais importantes e clássicos itens de moda para todas as gerações em especial a Y e Z. Aplicar batom é uma das maneiras mais populares e baratas das mulheres realçarem feminilidade e beleza.

O batom é visto como uma maquilagem capaz de alterar a aparência física quando utilizado, e de acordo com Gilles Lipovetski (2004) estamos vivendo um momento social onde a busca pela beleza, passa a ser feita a qualquer preço e esta é uma das características da vaidade.

O batom é usado pelas mulheres através de muitas décadas. Onde uma série de vantagens sociais associadas ao uso de maquilagem labial passa a estabelecer uma identidade feminina. O uso do batom, é uma importante forma através da qual as mulheres gerenciam a impressão e demonstram a evolução de sua personalidade quando desempenham papéis sociais e profissionais

\section{PROCEDIMENTOS METODOLÓGICOS}

A pesquisa realizou-se com o uso do processo qualitativo. A escolha dessa investigação justifica-se pelo fato da pesquisa qualitativa ser um método usado para a coleta de dados e informações baseados na experiência e comportamento humano, usado em áreas onde o comportamento e modo de organização social são focalizados. Seu foco principal é a interpretação da análise e forma de cenários pré-determinados, entendendo os aspectos constituintes das relações estabelecidas entre indivíduos e objetos, consumidores e mercado (Denzim \& Lincoln, 2006).

Foram pesquisadas dez mulheres por meio de entrevistas individuais em profundidade. A escolha das participantes respeitou os limitadores e as respondentes foram voluntárias e candidataram-se para as entrevistas. Divulgou-se à uma turma de graduação em Administração de uma faculdade de São Paulo, situada na região sul no bairro do Jardim Consórcio, que atendiam aos critérios de renda e faixa etária. 
Os sujeitos de pesquisa estavam na faixa etária entre 18 e 34 anos. Entendeu-se que o escopo de idade escolhido constitui pessoas pertencentes à geração $\mathrm{Y}$ e $\mathrm{Z}$ - como atestam Veloso, Dutra e Nakata (2008), onde a geração Y corresponde aos nascidos entre os anos de 1978 a 1988, e os nascidos entre 1989 a 1999 corresponde à geração Z, pertencentes à classe C, de profissões distintas e residentes em São Paulo - SP. Aplicou-se um questionário socioeconômico para delimitar o estrato econômico ao qual estavam inseridas as participantes do estudo, estipulou-se como requisito para a pesquisa que se encontrassem estrato referente à classe $\mathrm{C}$ (com renda mensal domiciliar entre $\mathrm{R} \$ 1.064,00$ e $\mathrm{R} \$ 4.561,00)$, de acordo com estudo de Neri(2011).

A escolha das duas técnicas de coleta de dados deu-se com o objetivo de entender o comportamento dentro de um grupo,obtendo-se uma quantidade de informações entendida por Malhotra (2012) como a função ideal do grupo focal, e de obter de forma aprofundada um grupo escolhido de indivíduos com características semelhantes aos do grupo focal, utilizandose de entrevistas em profundidade. Esses dois métodos de coleta de dados possibilitou credibilidade às considerações da pesquisa, graças às potencialidades para aprender dados aprofundados quanto a informações de um aspecto da realidade, que não pode ser quantificado (Bauer \&Gaskel, 1999).

Optou-se por estudar um grupo de indivíduos a partir do critério de renda e idade e que apresentassem perfis socioeconômicos semelhantes (Geração Y e Z e Classe C). Os entrevistados responderam a um questionário estruturado com informações socioeconômicas para verificar se tinham o perfil. O grupo de foco teve duração de cerca de 10' com cada entrevistada. A localidade para a realização da pesquisa foi na cidade de São Paulo, capital, na Faculdade de São Paulo.

O grupo de foco foi uma das técnicas de coleta, por se tratar da melhor forma de se obter conhecimento, vindo de um grupo social. A técnica de coleta de dados foi direcionada às questões pertinentes ao estudo, sendo aplicadas pela entrevistadora individualmente com cada entrevistada, e foram planejadas com apoio de um roteiro estruturado, onde as entrevistas foram agendadas pessoalmente e individualmente com as entrevistadas selecionadas. Como complemento à técnica do grupo focal, as entrevistas foram transcritas para análise, para examinar-se o grau de aprofundamento dos fatores ao qual se propôs na pesquisa. A técnica apresentou-se adequada neste contexto, pois consegue captar mensagem emitida por entrevistados com uma postura mais franca e aberta (Bauer \&Gaskell, 2005; Marconi \&Lakatos, 1999).

65 Revista Competitividade e Sustentabilidade - ComSus, Paraná, v. 3, n. 1, p. 53-71, Jan /Jun. 2016. 
O perfil das entrevistadas foi descrito no Quadro 1

\begin{tabular}{|c|c|c|c|c|c|}
\hline $\mathbf{N}^{0}$ & IDADE & COLETA & GÊNERO & $\begin{array}{l}\text { FAIXA } \\
\text { SALARIAL } \\
\text { MÊS RS } \\
\end{array}$ & PERFIL \\
\hline 1 & 25 & $\begin{array}{l}\text { Grupo de } \\
\text { foco }\end{array}$ & Feminino & 700,00 & $\begin{array}{l}\text { Postura retraída, cuidadosa, veste-se de maneira } \\
\text { clássica. }\end{array}$ \\
\hline 2 & 23 & $\begin{array}{l}\text { Grupo de } \\
\text { foco }\end{array}$ & Feminino & $1.200,00$ & $\begin{array}{l}\text { Postura desinibida, questionadora, veste-se de } \\
\text { maneira casual e na moda. }\end{array}$ \\
\hline 3 & 28 & $\begin{array}{l}\text { Grupo de } \\
\text { foco }\end{array}$ & Feminino & $2.000,00$ & $\begin{array}{l}\text { Postura retraída, inibida , porém demonstra ser } \\
\text { equilibrada, veste-se de maneira casual com } \\
\text { simplicidade. }\end{array}$ \\
\hline 4 & 30 & $\begin{array}{l}\text { Grupo de } \\
\text { foco }\end{array}$ & Feminina & $1.000,00$ & $\begin{array}{l}\text { Postura desinibida, confiante, brincalhona, veste- } \\
\text { se com simplicidade. }\end{array}$ \\
\hline 5 & 34 & $\begin{array}{l}\text { Grupo de } \\
\text { foco }\end{array}$ & Feminino & $1.800,00$ & $\begin{array}{l}\text { Postura retraída, flexível, questionadora, prática e } \\
\text { objetiva, veste-se na moda e gosta d cores } \\
\text { vibrantes. }\end{array}$ \\
\hline 6 & 34 & $\begin{array}{l}\text { Grupo de } \\
\text { foco }\end{array}$ & Feminino & $2.500,00$ & $\begin{array}{l}\text { Postura confiante, desinibida, calma e equilibrada, } \\
\text { veste-se de modo simples. }\end{array}$ \\
\hline 7 & 33 & $\begin{array}{l}\text { Grupo de } \\
\text { foco }\end{array}$ & Feminino & $4.500,00$ & $\begin{array}{l}\text { Postura extrovertida, explosiva, consumista, veste- } \\
\text { se sempre na moda e faz questão de estar } \\
\text { apresentável. }\end{array}$ \\
\hline 8 & 27 & $\begin{array}{l}\text { Grupo de } \\
\text { foco }\end{array}$ & Feminino & 800,00 & $\begin{array}{l}\text { Postura prática, flexível, é questionadora, porém } \\
\text { objetiva, veste-se de forma simples. }\end{array}$ \\
\hline 9 & 30 & $\begin{array}{l}\text { Grupo de } \\
\text { foco }\end{array}$ & Feminino & $1.500,00$ & $\begin{array}{l}\text { Postura retraída, observadora, gosta de estar na } \\
\text { moda, cuida da aparência e estética. }\end{array}$ \\
\hline 10 & 21 & $\begin{array}{l}\text { Grupo de } \\
\text { foco }\end{array}$ & Feminino & $1.200,00$ & $\begin{array}{l}\text { Postura inibida veste-se na moda, é ponderada e } \\
\text { acompanha a moda. }\end{array}$ \\
\hline
\end{tabular}

Fonte: Autora Sandra Maria

\subsection{Análise dos Dados}

O exame dos dados obtidos foi realizado pela técnica de análise de conteúdo, um método de pesquisa que estuda comunicações e diálogos com o objetivo de delinear e explanar seu conteúdo de forma ordenada e objetiva.

O autor de uma pesquisa de base qualitativa capta dado e informações, cujo conteúdo exige ordenação para que se faça a interpretação (Denzin \& Lincoln, 2006; Cooper \& Schindler, 2003; Bardin, 1977; Bauer \&Gaskel, 1999). Tanto o grupo de foco como as entrevistas foram registradas através de um relatório e questionário por escrito, e foram transcritos, transformando os dados coletados em material linguístico. Considerou-se a categorização de análise ao estudo, por ser usada em contextos ligados a averiguações sociais e por viabilizar a decodificação e descrição de teor de qualquer espécie de informações e textos, propiciando acesso a elementos enriquecedores provindos das falas dos entrevistados (Bardin, 1977; Bauer \&Gaskel, 2013). 


\section{RESULTADOS}

Este estudo apontou que o batom é um componente de compra importante para as mulheres da classe $\mathrm{C}$, que fazem parte da geração $\mathrm{Y}$ e $\mathrm{Z}$, seu consumo é parte integrante de seus itens de compra.

O hábito de comprar batom faz parte do cotidiano destas mulheres identificadas como classe C e geração Y e Z (Veloso, Silva \& Dutra, 2011; Hudson, -2010; Veloso, Dutra e Nakata, 2008) onde as entrevistas deixam claro que a marca Avon é percebida como a preferida.

As entrevistadas enfatizam o quanto a cor precisa ser bonita e vibrante, e que a compra deste produto é feita através do catálogo de produtos da empresa através de uma revendedora, e poucas entrevistadas tem o hábito de comprar o produto em um ponto de venda.

As entrevistadas reforçam o quanto é importante a embalagem e que esta traduz a qualidade do produto batom, e aqui se percebe um ponto relevante, que as entrevistadas colocam que compram com os olhos, e que a cor da embalagem é um fator importante, e a preferência é para as cores preto e vermelho, sendo o material adequado para o conteúdo do produto o plástico e o acrílico, e para o visual o papelão ou outro material reciclável.. A cor do batom é o fator principal para a compra, e decisão de uso diário do batom, mas o humor no momento da compra tem influência na sua decisão final.

\section{DISCUSSÃO}

O objetivo deste estudo exploratório foi o de investigar as motivações presentes num grupo de mulheres integrantes da classe $\mathrm{C}$, pertencentes às gerações $\mathrm{Y}$ e $\mathrm{Z}$ no consumo de batom (cremoso, líquido e brilho).

Este artigo é uma forma de contribuir para um maior entendimento sobre o tema e trazer informações para vários setores da economia brasileira, possibilitando às empresas um melhor conhecimento deste grupo social e entendimento do que esta consumidora deseja, em termos de produto e marca.

A teoria das gerações utilizada neste estudo foi fundamental para se compreender as transformações ocorridas no ciclo de vida de um indivíduo, principalmente da geração Y e Z, por ser caracterizada por forte influência de tecnologia no seu cotidiano, além de traços de individualidade constituídos como forma de ter a sensação de pertencimento social (Lancaster, 2011, Santos, 2011; Meyers, 2005; Damatta, 2000) associado ao ato de obter um bem pessoal, como o batom.

67 Revista Competitividade e Sustentabilidade - ComSus, Paraná, v. 3, n. 1, p. 53-71, Jan /Jun. 2016. 
Um ponto que merece discussão neste artigo, baseado nos resultados desta pesquisa, é com relação ao local de compra do produto batom, onde as entrevistadas não mencionaram comprar este produto em um ponto de venda e sim através de catálogo, o que pode ser um fator relevante para se entender o por quê da falta desse hábito para este público em uma nova pesquisa.

\section{CONSIDERAÇÕES FINAIS}

Este estudo teve por objetivo verificar os aspectos que motivam um grupo de mulheres integrantes da classe $\mathrm{C}$, pertencentes à geração $\mathrm{Y}$ e $\mathrm{Z}$, à realizar a compra do produto batom.

A pesquisa demonstrou que o consumo de batom, no grupo estudado é parte integrante de seus itens de compra, e adquirir um batom é considerado um hábito que faz parte do cotidiano das mulheres identificadas como classe C e geração Y e Z (Veloso, Silva \& Dutra, 2011; Hudson, 2010; Veloso, Dutra e Nakata, 2008).

As entrevistadas demonstraram ter percepção com relação à marca escolhida e enfatizaram o quanto a cor influência na compra, na decisão e uso do batom.

A embalagem foi outro fator considerável nesse estudo pois reflete a qualidade do produto, onde se identificou através das entrevistadas que as integrantes deste grupo compram com os olhos, aqui vários estudos já identificam a cor, a embalagem e a marca, como estímulos do comportamento do consumidor, e as participantes desta pesquisa declararam suas preferência de cores, para embalagem e o material que acreditam ser adequado para o conteúdo do batom.

Foram apresentados neste trabalho, conceitos e esclarecimentos quanto ao comportamento de consumo, características da variável vaidade, características da classe $\mathrm{C}$, práticas dos jovens da geração $\mathrm{Y}$ e $\mathrm{Z}$, e história e mercado do batom.

Após a aplicação dos métodos de pesquisa, os dados foram analisados e concluídos.

O presente estudo não pode ser visto como uma generalização, pois o método escolhido é de natureza qualitativa, onde outras pessoas, em outro momento, podem apresentar variação nos resultados obtidos. Deve-se levar em conta a subjetividade envolvida nas interpretações dos dados que foram coletados pelas autoras do estudo. 


\section{REFERÊNCIAS}

Agostini, Renata. MEYER, Carolina. A Classe C cai na rede. Revista Exame, São Paulo/SP, edição 978, ano 44, nº 19. P. 35 - 45. Outubro, 2010.

Anpad. 2010. Salvador. Disponível em

http://www.anpad.org.br/trabalho_popup.php?cod_edicao_trabalho=15896. Acesso em 10 de dezembro de 2010.

Bardin, L. (1977). Análise de conteúdo. Lisboa, Edições 70.

Bauer, M.W. \& Gaskell, G. (2013) Pesquisa Qualitativa com Texto, Imagem e Som Um Manual prático. $11^{\mathrm{a}}$ edição Petropólis, RJ, Vozes.

Barbosa, Lívia. Sociedade de Consumo. Rio de Janeiro: Jorge Zahar, 2004.

Barbosa, Lívia; Campbell, Colin. Cultura, Consumo e Identidade. Rio de Janiero. Ed. $\mathrm{FG}, 2006$.

Blackwell, Roger D.; Miniard, Paul W.; Engel, James F. Comportamento do Consumidor.São Paulo: Cengage Learning, 2008. $9^{\text {a }}$ Ed. Traduzido por Eduardo Ayrosa e equipe.

Campbell, Colin. "Eu compro, logo sei que existo: as bases metafísicas do consumo moderno".

Cordeiro, H. T. D., Freitag, B. B., Fischer, A. L., ALBUQUERQUE, L, G., Gestão de Gerações 2013.

Cooper, D.R. \& Schindeler, P. S. (2003) Métodos de Pesquisa em Administração. $7^{a}$ edição. Porto Alegre. Bookman.

Denzin, K.K. \& Lincoln, Y.S. (2006). O Planejamento de pesquisa qualitativa? Teorias e abordagens. $2^{\text {a }}$ edição. Porto Alegre. Artmed.

Gade, C (1998). Psicologia do consumidor e da propaganda. São Paulo. EPU

Gandolpho, Cibele. Brasil é o terceiro no mundo no consumo de cosméticos. Diário de São Paulo. Publicado em 10 de agosto de 2007. Disponível em

http://oglobo.globo.com/economia/mat/2007/08/10/297230396.asp, acesso em 5 de dezembro de 2010 .

Gouveia, Katiane. O comportamento do consumidor de baixa de renda. Semana da pequena empresa SEBRAE. 17 a 21 de Novembro. São Paulo - SO. 2008.

Ibge. Classes Sociais no Brasil. Disponível em

http://www.ibge.gov.br/series_estatisticas/subtema.php. Acesso em 22 de novembro de 2010.

Lancaster, L.C. (2011) Y da questão: como a geração Y está. São Paulo. Saraiva.

69 Revista Competitividade e Sustentabilidade - ComSus, Paraná, v. 3, n. 1, p. 53-71, Jan /Jun. 2016. 
Lima, Renato de Oliveira. O Consumo feminino de cosméticos anti-sinais. In: Encontro da Associação nacional de Pós Graduação e Pesquisa em Administração -

Lipovetsky, Gilles e Charles, Sébastien. Os Tempos Hipermodernos. São Paulo: Barcarolla, 2004.

Marconi, M.D.A. \& Lakatos, E.M. (1999). Técnicas de Pesquisa: planejamento e execução de pesquisa, amostragem e técnicas de pesquisa, elaboração, análise e interpretação de dados. $4^{\mathrm{a}}$ edição. São Paulo. Editora Atlas.

Meyers, D. (2005). Introdução à psicologia geral. Rio de Janeiro: Livros técnicos e científicos

Mowen, J., Longoria, A. \& Sallee, A. (2009). Burning and Cutting: identifying the traits of individuals with an enduring propensity to tan and to undergo cosmetic surgery . Journal of Consumer Behavior, 8, 238-25.

Neri, Marcelo. A Nova Classe C - O Lado Brilhante da Pirâmide: Saraiva, 2012

Oliveira, S. (2010) Geração Y: o nascimento de uma nova versão de líderes. São Paulo. Integrare Editora.

Naresh K. Malhotra. Pesquisa de Marketing: Uma orientação Aplicada.Editora: Bookman.2012 $6^{\mathrm{a}}$ edição

Netemeyer, R., Burton, S. \& Linchstenstein, D.. (1995). Vanity: traits aspects of vanity In W. Bearden \& R. Netemeyer. Handbook of marketing scales: multi-item measures for marketing and consumer behavior research (pp.48-49). California: Sage Publications.

Porschman, Marcio. A Nova Classe Média. Bointempo,2012

Rocha, Angela da e SILVA, Jorge Ferreira da (orgs.). Consumo na base da pirâmide- estudos brasileiros. Rio de Janeiro: Mauad X, 2009.

Roger, C. Classe C apresenta novos hábitos de consumo. Disponível em

http://www.makeweb.com.br/makepress/classe-c-apresenta-novos-habitos-de-consumo.

Acesso em 5 de dezembro de 2010.

Schouten, J. W. Selves in transition: Symbolic Consumption in Personal Rites of Passage and Identity Reconstruction. Journal of Consumer Research, Gainesville, v. 17, n. 4, p. 412-424,

1991.

Solomon, Michael R. O comportamento do consumidor: comprando, possuindo e sendo. 5. ed. Porto Alegre: Bookman, 2002.

Veloso, E. F. R.; Silva, R. C.; Dutra, J. S.; Gestão de Gerações, 2012.

Volpi, Alexandre. A História do consumo no Brasil. Rio de Janeiro: Elsevier, 2007. 
Zemke, R.; Raines, C.; Filipczak, B. Generations at work: Managing the clash of veterans, boomers, xers, and nexters in your workplace. Nova York: AMACOM, 2000.

\section{NOTAS}

${ }^{1}$ Graduada em Economia pela Universidade de São Paulo (1989) e doutora em Administração de Empresas pela Fundação Getúlio Vargas-SP (1998). Cursou um ano de doutorado com bolsa Sanduíche CAPES na Georgia State University (1996-1997) e foi Associate Professor na Quinnipiac University no Departamento de Marketing de 2001 a 2002. E-mail: claudiaraac@gmail.com

${ }^{2}$ Mestre em Administração pelo Centro Universitário da Faculdade Metropolitanas Unidas de São Paulo/SP. MBA em Gestão de Negócios pela FAAP - SP. Pós-Graduada em Marketing pela Escola Superior de Propaganda e Marketing de São Paulo/SP . Administração de Empresas a pela Pontifícia Universidade Católica de São Paulo - PUC - Email: caparrozmm@gmail.com

${ }^{3}$ Mestre em Administração pelo Centro Universitário da Faculdade Metropolitanas Unidas de São Paulo/SP (2015), Pós-Graduada em Marketing pela Escola Superior de Propaganda e Marketing de São Paulo/SP (1991), Psicóloga pela UniPaulistana- Centro Universitário Paulistano de São Paulo/SP (1982) - Brasil - Email: sandramaria.martini@gmail.com

71 Revista Competitividade e Sustentabilidade - ComSus, Paraná, v. 3, n. 1, p. 53-71, Jan /Jun. 2016. 